\title{
Structural Study of Mordenite from Mátra Mts. (N-Hungary): Dachiardite Moduls Reduce Channel Size in Mordenite
}

\author{
Szilvia Ormándi ${ }^{1 *}$, Ildikó Cora ${ }^{2}$, Zsolt Dallos ${ }^{1}$, Ferenc Kristály ${ }^{3}$ and István Dódony ${ }^{1}$ \\ ${ }^{1}$ Department of Mineralogy, Eötvös Loránd University, Pázmány Péter sétány. 1/CBudapest, 1117 Hungary \\ ${ }^{2}$ Institute for Technical Physics and Materials Science, Centre for Energy Research, Hungarian Academy of Sciences, \\ P.O. Box 49, H-1525 Budapest, Hungary \\ ${ }^{3}$ Institute of Mineralogy and Geology, University of Miskolc, Miskolc, Egyetem út, 3515 Hungary
}

Received: 07 June 2017; accepted: 01 September 2017

\begin{abstract}
Zeolites are crystalline microporous alumosilicates whose unique pore and channel systems are the reason for their important role in catalysis, separation, and ion exchange. This work focuses on the morphology and structure of a natural zeolite, mordenite. Our samples were collected at Lengyendi-galya (Gyökeres-tetö) in the Mátra Mountains (NE-Hungary). Zeolite samples were investigated by X-ray powder diffraction, scanning, and transmission electron microscopy. Mordenite has typically fibrous appearance and occurs in association with other zeolites such as heulandite and chabazite. Based on intense streaks and superlattice reflections in selected area electron diffraction patterns, we identified planar faults in the structure. A single fault produces a dachiardite-type structural slab within the mordenite lattice, reducing its channel size.
\end{abstract}

Keywords: Natural mordenite, structure, diffraction, faults

\section{Introduction}

Zeolites have complex alumosilicate frameworks. These frameworks contain large channels and interconnected cages. We use zeolites in gas and petroleum industry, water softening, sewage treatment, agriculture, paper production, and radioactive waste treatment, as well as in construction materials. The structural channels and voids are occupied by loosely bound cations and water
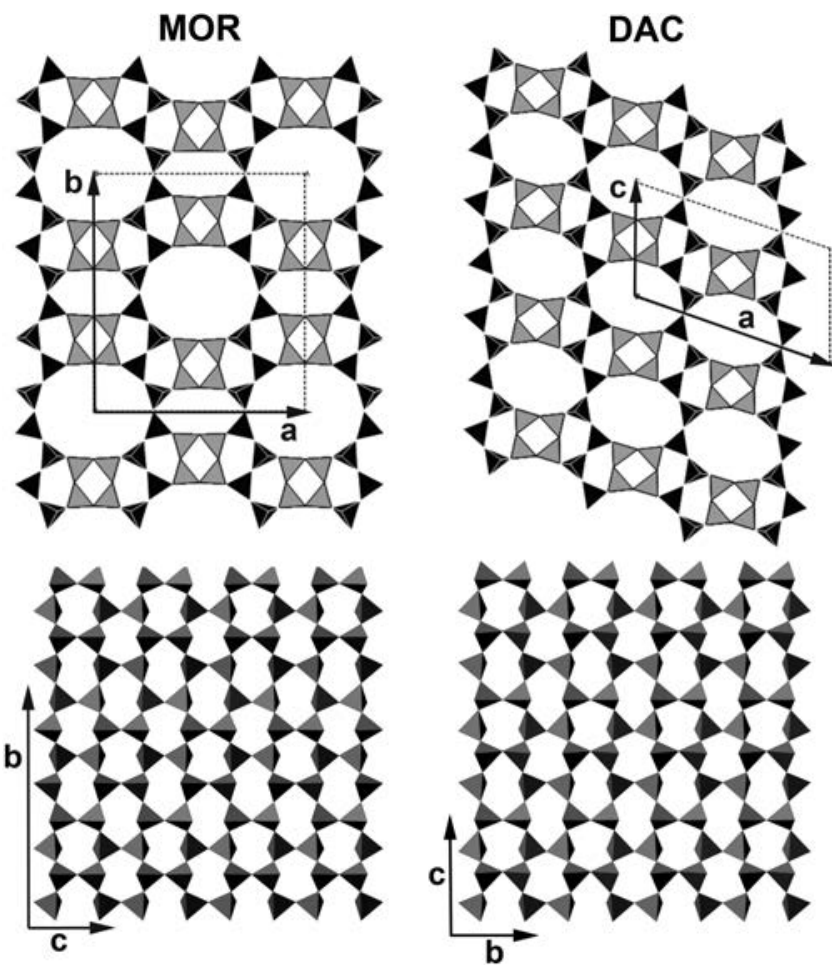

Figure 1. The mordenite framework projected along the $c$ axis $(\mathrm{Cmcm}$, $a=18.1, b=20.5, c=7.5 \AA)$ and dachiardite along the $\boldsymbol{b}$ axis $(C 2 / m$, $\left.a=18.6, b=7.5, c=10.4, \beta=108.9^{\circ}\right)[10]$. The structure is composed of puckered (100) sheets (black tetrahedra at the upper half of the figure). The puckered tetrahedral sheets of mordenite and dachiardite are shown at the lower part of the figure

\footnotetext{
* Author for correspondence: ormszi12@gmail.com
}

molecules that can be removed and replaced without disrupting the tetrahedral framework. This unique - so-called, zeolitic - property makes a zeolite structure the best candidate to perform cation exchange, adsorption, and molecular sieving (passing a gas or liquid through a zeolite). Zeolites can be used in dehydration and rehydration processes and can be resistant to high energy radiation [1].

The mordenite group includes the minerals mordenite, dachiardite, epistilbite, ferrierite, and bikitaite [2, 3]. Zeolites in the mordenite group are built by five-membered rings of tetrahedra - this is called the secondary building unit - and puckered sheets made of six-membered rings of tetrahedra parallel to (100), which ensure a perfect prismatic cleavage (Figure 1). Parallel to the $c$ axis, there are channels formed by twelve-membered rings (12MRc: aperture, $6.5 \times 7.0 \AA$ ) and compressed eight-membered rings (8MRc: aperture, $5.7 \times 2.6 \AA$ ). There are another eight-membered rings, and channels also occur parallel to $\boldsymbol{b}(8 \mathrm{MRb}$ : aperture, $3.4 \times 4.8 \AA)$ (Figure 2). In dachiardite, ten-membered rings are parallel to $\boldsymbol{b}$ (Figure 1) and there are also compressed eight-membered rings

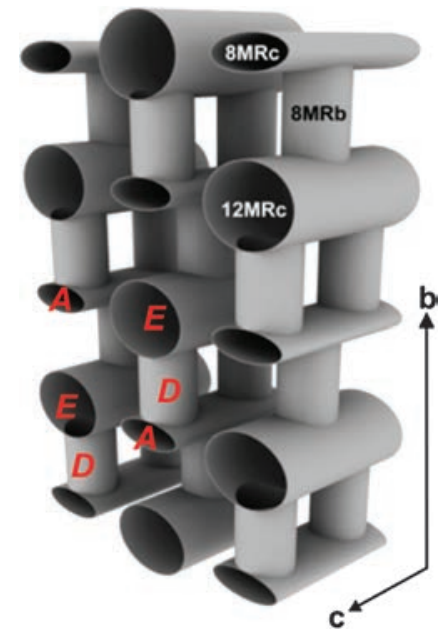

Figure 2. The channel system of the mordenite structure with the three main tubes, bordered by 12-, 8-, and 8-membered rings of tetrahedra along $\boldsymbol{c}, \boldsymbol{c}$, and $\boldsymbol{b}$, respectively (12MRc, $8 \mathrm{MRc}$, and $8 \mathrm{MRb}$ ). These tubes form only one-dimensional passageways [4]. The locations of the extraframework $\mathrm{A}, \mathrm{D}$, and $\mathrm{E}$ cations are labeled in red 


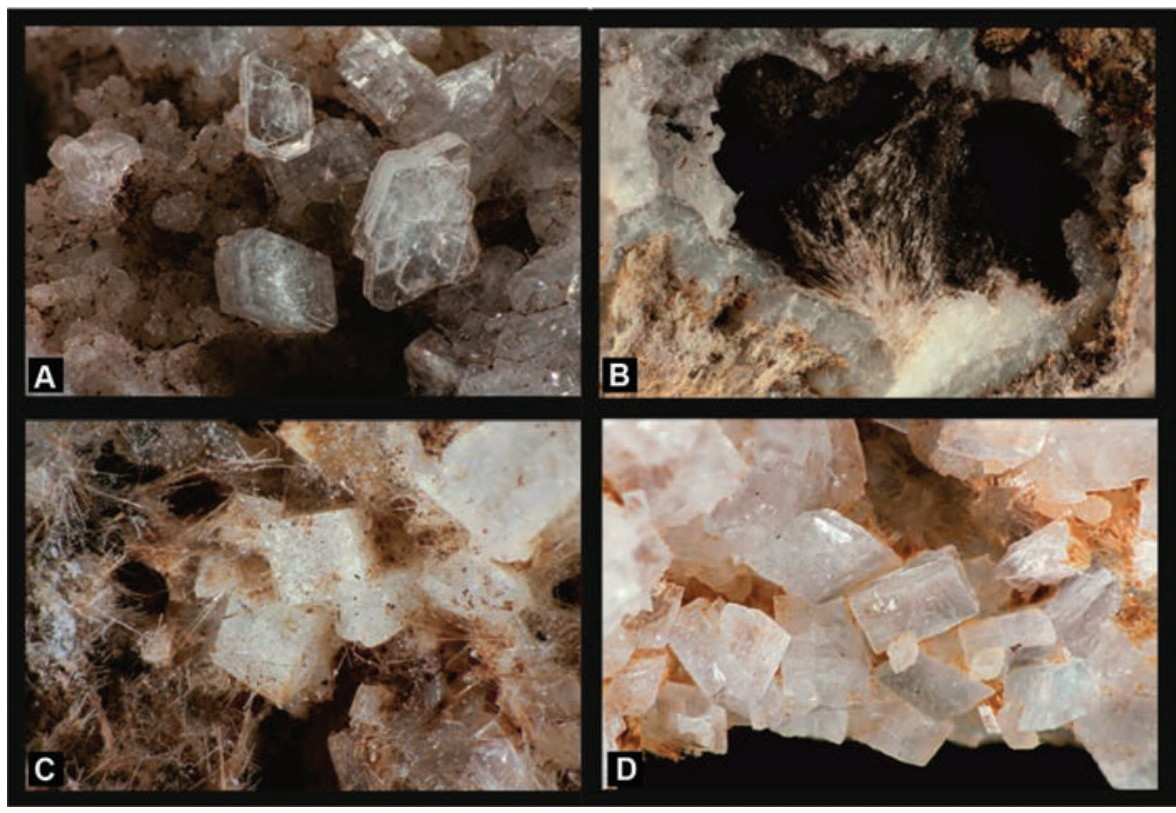

Figure 3. Stereomicroscopy images of zeolites from Gyökeres-tetö. A - heulandite pseudo-hexagonal plates. B and C - heulandite and mordenite crsytals. D - chabazite rhombohedra (the width of images in mm: A, 10.9; B, 13.6; C, 6.8; D, 6.9)

parallel to the $c$ axis [4]. Extraframework cations in mordenite occupy mainly three sites. Two of these sites are close to the fourmembered Al-enriched rings (light-gray shaded tetrahedra in Figure 1) and are located in the connecting channels parallel to the $\boldsymbol{b}$ axis; the A site is in the center of the compressed eightmembered ring channels, whereas the $\mathrm{D}$ site is near the center of the eight-membered ring, connecting to the wide channel. The E site is in the large channels (Figure 2).

The ideal mordenite composition is $\left(\mathrm{Na}_{2}, \mathrm{~K}_{2}, \mathrm{Ca}\right)_{4}\left[\mathrm{Al}_{8} \mathrm{Si}_{40} \mathrm{O}_{96}\right]$. $28 \mathrm{H}_{2} \mathrm{O}$; the structure is orthorhombic with space groups of Cmcm $(a=18.11, b=20.46, c=7.52 \AA, Z=1)$ [5]. The symmetry lowering from $\mathrm{Cmcm}$ to $C m c 2_{1}$ occurs when locations of extraframework cations are asymmetric [6].

Mordenite is one of the zeolites which have very good absorption and separation properties. For this reason, Barrer [7] examined this type of zeolite framework and synthesized mordenite with a small port ("port" meaning the channels in the structure). Therefore, two different structural varieties are now distinguished - large-port and small-port mordenite - by the accessibility of 12-membered ring channels (Figure 1). In the small-port mordenite, molecules fit with sizes less than $4.2 \AA$ in diameter in the channels, and in the large-port mordenite, the channels are accessible for molecules larger than $4.2 \AA$ [8]. Mordenite as a mineral typically has the properties of small-port mordenite. The widely accepted explanation for the different port sizes is that stacking faults disrupt the large port structure, resulting in channels of smaller diameter [9]. In the present study, we examine a mordenite mineral specimen, in order to understand the structural difference between the large- and small-port variants.

\section{Experimental}

The locality of the measured samples is Lengyendi-galya (Gyökeres-tetö), Mátra Mountains (NE-Hungary). The mordenite

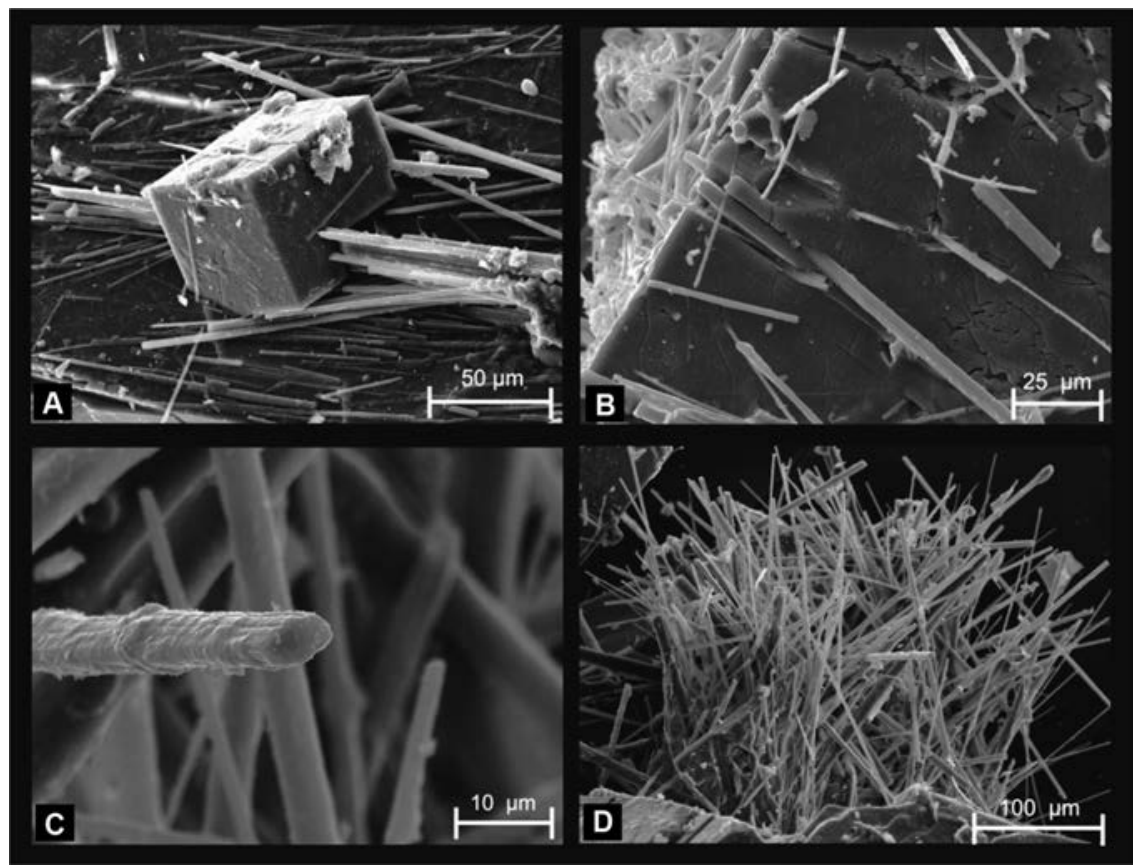

Figure 4. SE images of mordenite and heulandite from Gyökeres-tető. A and B - heulandite overgrows the first formed mordenite fibers. C and D - typical mordenite fibers 


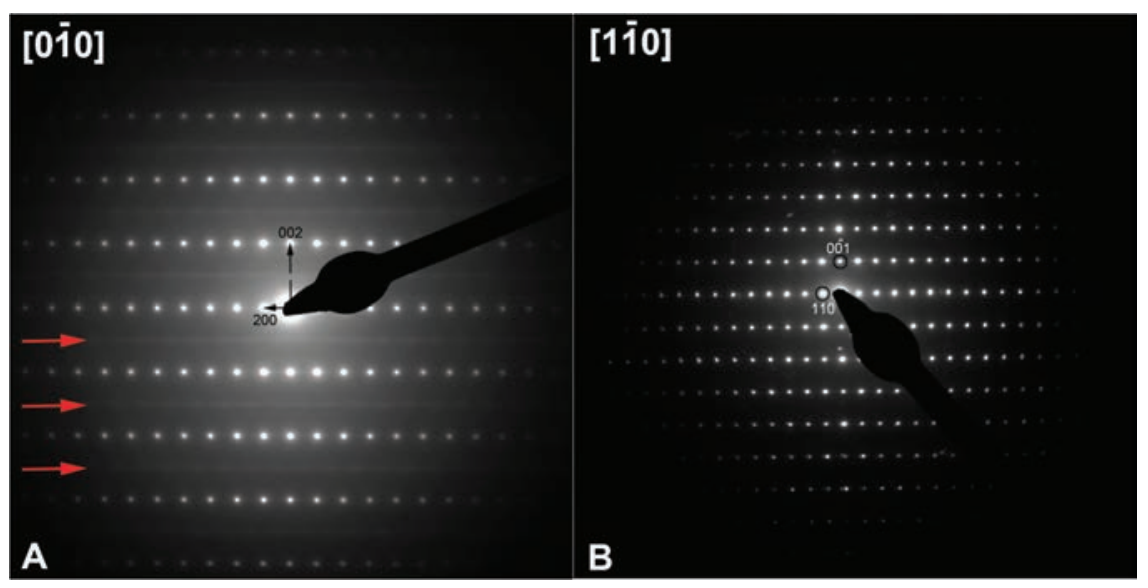

Figure 5. SAED patterns of mordenite. $h+1$ odd reflections appear which are forbidden in the $C m c 2_{1}$ space group

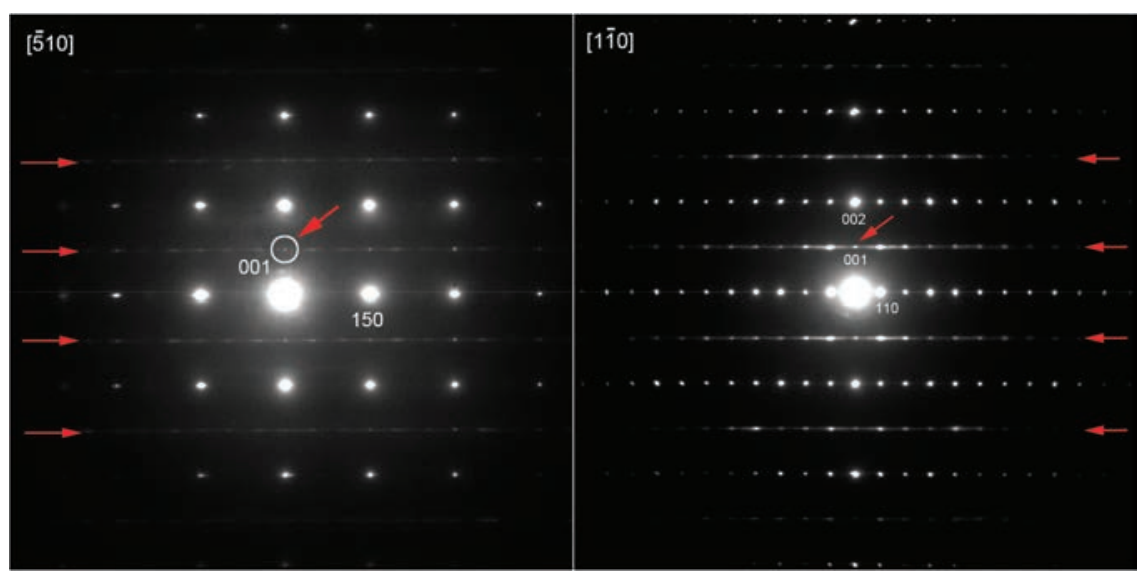

Figure 6. SAED patterns obtained from mordenite. The red arrow indicates intense streaks along the lines of $h k l$ reflections where $l=2 n+1$

bundles occur in hydrothermally highly altered andesite. Pure mordenite sample was prepared from the andesite.

$\mathrm{X}$-ray diffraction measurements were carried out using Bruker D8 Advance diffractometer $\left(\mathrm{Cu}-\mathrm{K}_{\alpha}\right.$ source) with Göbbel-mirror, parallel beam geometry, equipped with Vantec1 position sensitive detector, with symmetrical $2.5^{\circ}$ axial Soller slits. Measurements were recorded in the $2^{\circ}-100^{\circ}(2 \Theta)$ angular range, with $0.007^{\circ}$ $(2 \Theta) / 140$ s goniometer speed. XRD patterns were evaluated by Search/Match in DiffracPlus EVA using ICDD PDF2 (2005) for crystalline components. Quantitative evaluation was performed in TOPAS4 with fundamental parameters approach, using crystal structures from ICSD database.

Morphological and textural observations were made using a Wild M400 stereomicroscope and an AMRAY 1830 scanning electron microscope (SEM). The crystal sturcture of mordenite was investigated by selected area electron diffraction (SAED), using a Philips CM20 transmission electron microscope operated at $200 \mathrm{kV}$. The composition was measured using Nanoprobe $\mathrm{X}$-ray microanalysis (EDS) with a Bruker system.

\section{Results and Discussion}

3.1. Appearance of mordenite and associated minerals. Using X-ray powder diffractometry, we measured the hydrothermally altered andesite, composed dominantly by mordenite and heulandite; other minerals include quartz, andesine, orthoclase, hematite, and smectite.

X-ray diffraction patterns recorded on $1 \mathrm{mg}$ powder sample. Rietveld measurements were carried out in TOPAS softvare in order to verify the powder purity. In the next step, peak search was done to prepare indexing data. Based on the measured reflections, we identified the Laue-group $2 / \mathrm{m} 2 / \mathrm{m} 2 / \mathrm{m}$ with C-centering. We observed forbidden reflections in the $C m c 2_{1}$ space group, so a reduced symmetry is evident for the bulk material.

Stereomicroscopy and secondary electron (SE) images revealed that the first product of hydrothermal alteration is mordenite, followed by heulandite (Figures 3 and 4). Secondary electron images in Figure 4A and B show heulandite crystals speared by mordenite fibers. Apparently, mordenite formed as the first zeolite and then heulandite grew around it.

3.2. Transmission electron microscopy. Features in SAED patterns from the mordenite fibers suggest a reduced symmetry compared to the $C m c 2_{1}$ space group and the presence of planar faults. We observed forbidden $h+l$ odd reflections in the $C m c 2_{1}$ space group. For example, in the [010] projection, $10 l, 30 l$, and $50 l$ reflections are present (red arrows show some $h 0 l$ lines in Figure 5A). Another example is the

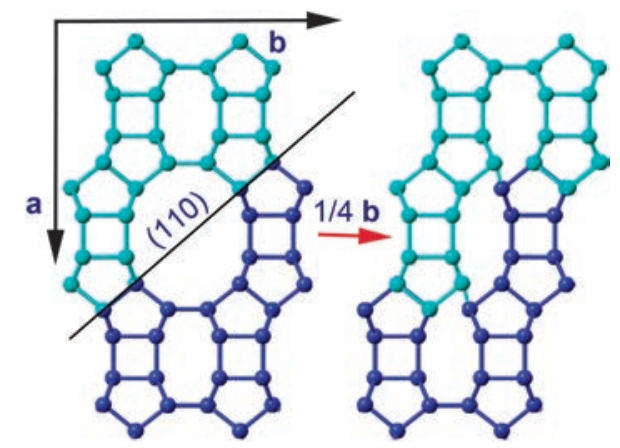

Figure 7. Representation of lattice displacement by a $\sim 1 / 4[010]$ vector in the mordenite framework, projected along [001]. If the turquoised part of the structure is translated by $1 / 4 \mathbf{b}$, a dachiardite-type slab results (see Figure 8B) 

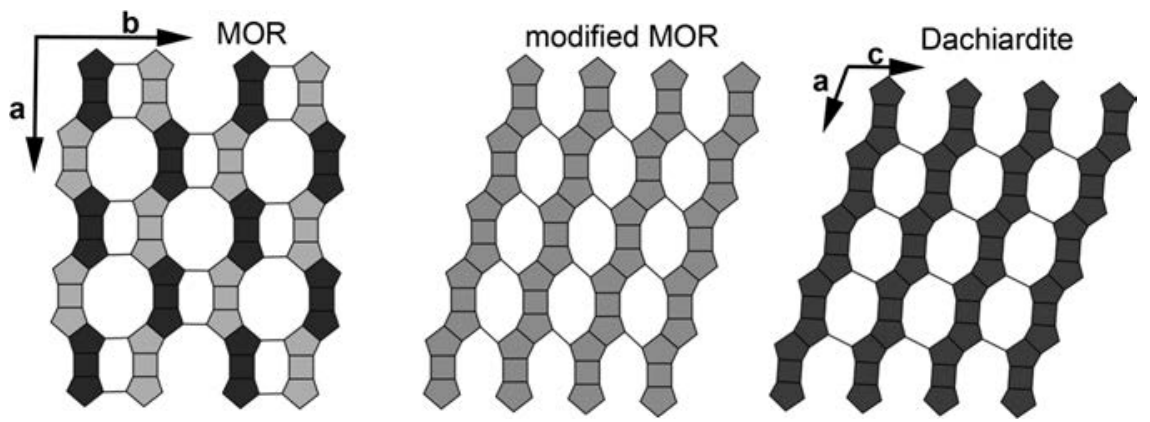

Figure 8. Changes in the mordenite structure as a result of planar faults. A) The original mordenite framework; B) mordenite modified by an array of $1 / 4$ [010] planar defects; and C) the new dachiardite-type part of the mordenite framework, after structure relaxation

[1 10$]$ projection in which $00 l(l=2 n+1)$ reflections are also visible (Figure 5B).

Intense streaks and superlattice reflections in SAED patterns of mordenite suggest the presence of planar faults. Figure 6 shows $[\overline{5} 10]$ and $[110]$ projected SAED patterns of mordenite, in which the lines of $h k l$ reflections with $l=2 n+1$ are interconnected by intense streaks, some of them marked with a red arrows.

The composition of mordenite was measured with EDS as $\left(\mathrm{Na}_{1.25} \mathrm{~K}_{0.42} \mathrm{Ca}_{1.67} \mathrm{Mg}_{0.21}\left[\mathrm{H}_{2} \mathrm{O}\right]_{28.9}\right)\left[\mathrm{Al}_{8.38} \mathrm{Si}_{40} \mathrm{O}_{96}\right]$. The correct $k$ factors were confirmed successfully on quartz and corundum earlier.

\section{Discussion}

Song et al. [11] observed different defect types in mordenite such as dislocations, planar defects, and local intergrowths using high-resolution electron microscopy (HREM) [11]. Planar faults with a $\sim 1 / 4$ [010] displacement vector result in the presence of dachiardite moduls in the structure. Based on intense streaks and superlattice reflections in SAED patterns, we also identified planar faults. Figure 6 shows examples of the mordenite reciprocal lattice in which the rows of $h k l$ reflections with $l=2 n+1$ are connected by intense streaks. This diffuse scattering is interpreted as an evidence of faults, where a fault produces a dachiarditetype structural slab within the mordenite lattice.

As shown by Figure 1, the puckered sheets are the same in mordenite and dachiardite, but the connection of these puckered sheets by four-membered rings (light shading) differs. The presence of the dachiardite domains affect the mordenite channel capacity by disrupting the system. Figure 7 shows the mordenite framework along [001]. With a displacement by a $\sim 1 / 4$ [010] vector (marked with a black arrow), dachiardite cages appear in the mordenite framework. This lattice displacement causes a surplus and a deficit of bonds which will connect by flipping (Figure 8B). The modified bonds are then relaxed in order to transform into a more stable structure (Figure 8C).

\section{Conclusions}

Space group determination from SAED patterns obtained from mordenite fibers suggested a symmetry reduction from $C m c 2_{1}$ to $2 / \mathrm{m} 2 / \mathrm{m} 2 / \mathrm{m}$ Laue group by the forbidden $h+1$ odd reflections and the evident $\mathrm{C}$-centering. Possible space groups include $C 222, C m m 2, C 2 m m, C m 2 m$, and $C m m m$. This symmetry is also confirmed by powder diffraction data of mordenite.

Acknowledgment. The authors gratefully thank István Gatter for his kind help in the fieldwork. The quality of the paper has been significantly improved by the valuable comments by M. Pósfai.

Open Access. This is an open-access article distributed under the terms of the Creative Commons AttributionNonCommercial 4.0 International License (https:// creativecommons.org/licenses/by-nc/4.0/), which permits unrestricted use, distribution, and reproduction in any medium for non-commercial purposes, provided the original author and source are credited, a link to the CC License is provided, and changes - if any - are indicated.

\section{References}

1. Tschernich, R. W. Geosience Press Inc. USA, 1992.

2. Meier, W. M. Natural Zeolites, Occurence, Properties, Use, Sand, L. B.; Mumpton, F. A. (eds) Pergamon Press, Oxford, 1978, 99-103.

3. Armbruster, T.; Gunter, M. E. Natural Zeolites: Occurrence, properties, applications in Bish, D. L.; Ming, D. W. editors. Reviews in Mineralogy \& Geochemistry, 2001, Vol. 45.

4. Simoncic, P.; Armbruster, T. Am. Mineral. 2004, 89, 421-431.

5. Meier, W. M. Z. Kristallogr. 1961, 115, 439-450.

6. Alberti, A.; Davoli, P.; Vezzalini, G. Z. Kristallogr., Kristallgeom., Kristallphys., Kristallchem. 1986, 175, 249-256.

7. Barrer, R. M. J. Chem. Soc. 1948, 2158.

8. Sand, L. B. Molecular Sieves Conference Papers, Meeting Date Society of Chemical Industry, London, 1967, 71-77.

9. Raatz, F.; Marcilly, C.; Freund, E. Zeolites 1985, 5, 329-333.

10. http://www.iza-structure.org/.

11. Song, S. G. J. Mater. Res. 1999, 14, 2616-2620. 